Psychology of Language and Communication 2015, Vol. 19, No. 3

DE GRUYTER

OPEN

DOI: $10.1515 /$ plc-2015-0011

DEIA GANAYIM

The Arab Center for Mind, Brain \& Behavior, Sakhnin

\title{
LETTER VISIBILITY AND THE OPTIMAL VIEWING POSITION EFFECT OF ISOLATED CONNECTED AND UN-CONNECTED LETTERS IN ARABIC
}

\begin{abstract}
The present study provides a further exploration of the role of Arabic letter visibility as a possible cause of the Optimal Viewing Position (OVP) effect. We used isolated connected and un-connected Arabic letters of different shapes (basic, initial, medial, final) placed at the center of fixation (Experiment 1) and at various possible positions in isolated presentation (Experiment 2). In order to investigate whether performance in the visual identification task is modulated by letter type, we presented each of the isolated connected and un-connected letter targets in each of the eleven stimulus positions across the array to produce a mean RT (ms) for each of the letter types. Using the initial fixation paradigm enabled us to compare reaction times with correctly identified letter targets appearing in the different possible positions. The findings of the present experiments demonstrated that visual letter recognition is influenced by: (i) the isolated letters' type (connected, un-connected), as connected letters are easier to recognize than un-connected letters; (ii) isolated letters' shape (basic, initial, medial, final), as medial and final are harder to recognize than basic and initial letter shapes; (iii) visual field, as reading rates were longer for letter stimuli that were presented in LVF compared to RVF; and (iv) eccentricity, as letter reading rates were correlated with their eccentric placement.
\end{abstract}

Key words: Arabic, optimal viewing position, visual recognition, connected, un-connected, isolated, letter

\section{Introduction}

It is now generally accepted that visual word recognition in languages with alphabetical orthographies involves identity processing of a word's component letters. Thus, text cannot be read if letters or words are not resolved (Falkenberg,

Address for correspondence: Deia Ganayim, The Arab Center for Mind, Brain \& Behavior (ACMBB), Sakhnin, Israel. E-mail: info@acmbb.org.il 
Rubin, \& Bex, 2007). Several researchers also agree that much of this processing should be performed in parallel (e.g., Grainger, 2008; Grainger \& Jacobs, 1996; McClelland \& Rumelhart, 1981).

Adelman, Marquis, Sabatos-Devito (2010) showed that among adult readers, letter identity encoding starts during the first $25 \mathrm{~ms}$ of printed word processing for all string positions simultaneously. However, the authors showed that while processing was initiated over the whole word letter string in parallel, all letters were not identified at the same level of efficiency (Reilhac, Jucla, Iannuzzi, Valdois, \& Démonet, 2012).

What factors influence our ability to identify letters? This question is important because it will help develop our understanding of the very first phase of reading processes, during which visual feature information is mapped (in parallel) onto position-coded letter identities in both central and peripheral vision (Grainger \& van Heuven, 2003; Marzouki et al., 2013).

One particularly useful approach for addressing this issue is to examine the process of letter identification. In this way, we can gather information about letter-level processing while minimizing the influence of higher-level phonological and semantic processes. The assumption here is that during visual word recognition, some form of letter-level processing must be performed before higher order codes come into play (Grainger, Granier, Farioli, Van Assche, \& van Heuven, 2006; Grainger \& van Heuven, 2003).

It is assumed that isolated letter perception is just a simplified case of visual object recognition (Pelli, Burns, Farrell, \& Moore-Page, 2006). Accordingly, letter identification is achieved by hierarchically organized layers of feature and letter detectors (Finkbeiner \& Coltheart, 2009; Grainger, Rey, \& Dufau, 2008; Selfridge, 1959; Selfridge \& Neisser, 1960). Research using psychophysical techniques has revealed that letters are identified via their constituent features (e.g., Jacobs, Nazir, \& Heller, 1989; Solomon \& Pelli, 1994).

The confusion matrix is the traditional evidence in favor of such an approach. In a typical experiment used to generate a confusion matrix, isolated letters are presented in data-limited conditions (brief exposures and/or low luminance and/ or masking) and erroneous letter reports are noted. Error rate (e.g., reporting F when E was presented) is hypothesized to reflect visual similarity driven by shared features. An analysis of the pattern of letter confusions was therefore expected to reveal the set of features used to identify letters. (Gibson, 1969; Geyer \& DeWald, 1973; Keren \& Baggen, 1981).

Several possible forms of mental representations (categories) have been suggested in the literature as underlying the processing of isolated letters (Miller \& Vaknin, 2012): (1) abstract visual representations that depict the critical visual features of letters (e.g., Mycroft et al., 2002; Posner \& Mitchell, 1967); (2) abstract phonemic representations that represent the critical phonological characteristics of how letters are pronounced (e.g., Carrasco et al., 1988); (3) abstract nominal 
representations that is, letter names (e.g., Posner \& Mitchell, 1967); and (4) abstract non-code-specific representations that reflect the convention that two different letter shapes (e.g., A a) are the same letter (e.g., Kinoshita \& Kaplan, 2008; Miozzo \& Caramazza, 1998). It is worth mentioning that in the Arabic alphabet, the words for the different letters have similar voice onsets.

One well-established phenomenon in research investigating letter perception is that when fixating on the center of a letter array, performance is optimal for the central letter and then drops as a function of eccentricity (Averbach \& Coriell, 1961; Butler, 1975; Butler \& Merikle, 1973; Haber \& Standing, 1969; Merikle, Coltheart, \& Lowe, 1971; Merikle, Lowe, \& Coltheart, 1971; Mewhort \& Campbell, 1978; Nazir, Ben-Boutayab, Decoppet, Deutsch, \& Frost, 2004; Schwantes, 1978; Stevens \& Grainger, 2003; Wolford \& Hollingsworth, 1974). This is called the Optimal Viewing Position (OVP) and reflects a drop in visual acuity as a function of distance from fixation (Taydgat \& Grainger, 2009).

The importance of understanding mechanisms involved in letter identification has been well illustrated by previous findings showing that there is an asymmetry in the visibility of Latin letters to the left and right of fixation (Bouma, 1973; Kajii \& Osaka, 2000; Nazir, 1991; Nazir, Heller, \& Sussmann, 1992; Nazir, Jacobs, \& O’Regan, 1998). Nazir et al. (1992) measured letter visibility at various distances from the left and right of fixation. A drop in recognition performance depended not only on the distance from a fixation but also on the side of the presentation. At the same distance from fixation, letters to the right of fixation were easier to recognize than letters to the left. This asymmetry in Latin letter perception was previously reported by Bouma (1973) for the first and last letters of nonsense strings and has since been replicated for letters embedded in digits (Kajii \& Osaka, 2000). The present study assessed this phenomenon with Arabic letters.

Brysbaert and Nazir (2005) proposed that the OVP results from the interplay of numerous factors that play a role in visual word recognition. These factors, including lexical constraints, letter visibility, perceptual learning and hemispheric lateralization, may contribute jointly to OVP.

Perceptual learning based on reading habits affects the OVP since fixating on a word's beginning makes word recognition easier, because eyes tend to land at a word's beginning and frequently fixated locations improve reading performance (Nazir, Ben-Boutayab, Decoppet, Deutsch, \& Frost, 2004). Left-to-right-reading adults should be better at identifying words within the central or right-to-central part of their visual field because that is where they have adapted to visualize words while learning to read (Chung, Legge, \& Cheung, 2004). Yet, there is no clear leftward asymmetry of the OVP effect in languages read from right to left, such as Arabic or Hebrew (Farid \& Grainger, 1996; Nazir et al., 2004).

Hemispheric lateralization is another factor affecting the OVP since words presented in the left visual field (LVF) are projected to the right hemisphere $(\mathrm{RH})$, and information from the right visual field (RVF) is sent to the left hemi- 
sphere (LH) (Stevens \& Grainger, 2003), with the fovea of each eye divided precisely at its vertical meridian (Brysbaert, 2004; Jordan \& Paterson, 2009; Lavidor \& Walsh, 2004; Lindell \& Nicholls, 2003; Shillcock, Ellison, \& Monaghan, 2000). A word recognition advantage has been shown when letters in a word (or the entire word) are presented to the right of the fixation rather than the left. This reflects unilateral projection to $\mathrm{LH}$ and $\mathrm{RH}$ on either side of the fixation position (Paterson, Jordan, \& Kurtev, 2009), because the left cerebral hemisphere plays a greater role in language processing (Brysbaert, 1994, 2004) and split-fovea processing (Brysbaert, 1994; Brysbaert, Vitu, \& Schroyens, 1996; Hunter, Brysbaert, \& Knecht, 2007; Lavidor, Ellis, Shillcock, \& Bland, 2001; Martin, Thierry, Démonet, Roberts, \& Nazir, 2007). Whitney's (2001) SERIOL model argues that foveal letters assemble in the dominant hemisphere before recognition starts. This would mean that letters from a word's beginning (in RVF) are directly sent to the LH, but have to be temporarily inhibited until letters from the word's end (in LVF) are transferred from the RH to LH (Van der Haegen \& Brysbaert, 2011).

In a letter discrimination task, previous research has found (Bouma, 1973; Legein \& Bouma, 1977; Legge, Mansfield, \& Chung, 2001; Stevens \& Grainger, 2003) that the likelihood of correctly identifying a letter embedded in a string of homogeneous letters decreases faster in the left visual field compared to the right. For Latin letters, a complete visibility matrix across fixation positions and letter-in-string positions is available (Stevens \& Grainger, 2003). Yet, there is no such visibility matrix for Arabic letters.

\section{Arabic orthography}

Arabic orthography is unique and complex: dots are part of the grapheme, and letters have a similar basic form differentiated by the number and location of the dots (ث) - ت - D). Dots appear in 15 letters: 10 letters with one dot, 3 letters with two dots, and 2 letters with three dots, leading to great visual similarity between the letters. Some letters have different forms that depend on their position in the word, while the letter's basic form is preserved within these different forms (Abd El-Minem, 1987). Twenty-two out of 28 letters have 4 different letterforms (Table 1): a separate or basic form (॰), an initial form connecting to the left $(\bowtie)$, a medial form connecting to the right and left $(\&)$, and a final form connecting to the right (4). Since most of the Arabic letters are similar in their basic form, precise recognition of these Arabic letter-forms and their writing rules is essential for word recognition. This process consumes attentional resources (Abu Rabia, 2001), slowing the grapheme-phoneme conversion process (Taouk \& Coltheart, 2004).

Most of the letters connect from both sides (referred to as connecting letters), while six un-connecting letters (اذذدر) connect to the right only. Accord- 
Table 1. Isolated letter stimuli used in the different experiments

\begin{tabular}{|c|c|c|c|c|c|c|c|c|}
\hline & \multicolumn{4}{|c|}{ Connected Letters } & \multicolumn{4}{|c|}{ Unconnected Letters } \\
\hline & Basic & Initial & Medial & Final & Basic & Initial & Medial & Final \\
\hline 1 & ي & يـ & يـ & ي & د & د & $\lambda$ & $\lambda$ \\
\hline 2 & $d$ & t & هـ & 0 & و & و & g & $g$ \\
\hline 3 & $\dot{v}$ & $\dot{i}$ & 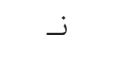 & $\dot{ن}$ & j & j & $j$ & $j$ \\
\hline 4 & p & $-a$ & - & a & $J$ & J & $\lambda$ & $\jmath$ \\
\hline 5 & \rfloor & $\Lambda$ & \lrcorner & J & j & j & $\dot{i}$ & $\dot{j}$ \\
\hline 6 & ك & s & s & ك & 1 & 1 & $L$ & $L$ \\
\hline 7 & ق & ق & ق & ق & د & د & 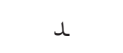 & 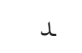 \\
\hline 8 & ف & ف & $\dot{\theta}$ & 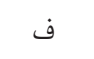 & و & و & 9 & g \\
\hline 9 & $\dot{\varepsilon}$ & $\dot{i}$ & $\dot{\varepsilon}$ & $\dot{\varepsilon}$ & j & j & $j$ & $j$ \\
\hline 10 & $\varepsilon$ & e & ع & $\varepsilon$ & 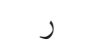 & J & $\jmath$ & $\jmath$ \\
\hline 11 & ظ & ظ & ظ & ظ & $\dot{j}$ & $\dot{~ j}$ & $\dot{i}$ & $\dot{i}$ \\
\hline 12 & b & b & $b$ & $b$ & 1 & 1 & $L$ & $L$ \\
\hline 13 & $\dot{\varphi}$ & ض & ض & $\dot{\omega}$ & د & د & $\lambda$ & 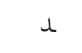 \\
\hline 14 & $\omega$ & ص ص & ص & $\infty$ & و & و & g & $g$ \\
\hline 15 & ش & ش & 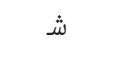 & ش & j & j & $j$ & $j$ \\
\hline 16 & w & m & 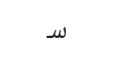 & $\omega$ & $\jmath$ & $\jmath$ & $\jmath$ & $\jmath$ \\
\hline 17 & $\dot{z}$ & $\dot{x}$ & $\dot{\gamma}$ & $\dot{\tau}$ & j & j & $\dot{i}$ & $\dot{i}$ \\
\hline 18 & $\tau$ & $x$ & $>$ & $\tau$ & 1 & 1 & $L$ & $L$ \\
\hline 19 & ج & $x$ & $ج$ & ج & j & j & j & j \\
\hline 20 & $\dot{ث}$ & $\hat{\imath}$ & ثـ & $\dot{ث}$ & و & و & g & g \\
\hline 21 & ت & ت & تـ & ت & j & j & $\dot{i}$ & $\dot{j}$ \\
\hline 22 & ب & 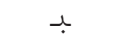 & بـ & ب & 1 & 1 & $L$ & $L$ \\
\hline
\end{tabular}

ingly (and distinctly from other languages), Arabic words can consist of one unit where the words contain no un-connecting letters (without inter-letter spaces: home يبت), or consist of several sub-units where the words contain several un-connecting letters (with inter-letter spaces: home راد). Consequently, Arabic orthography consists of words with different forms which depend on the number and position of the un-connecting letter strings in the word: connected words (without inter-letter spaces, where all the letters are connected), unconnected words (with inter-letter spaces, where most of the letters are unconnected), and mixed words (with some inter-letter spaces, where some letters are connected and some are not). A previous study found that in a corpus of 262,647 words, the average number of letters was 4.3 , with a sub-unit average of 2.2 per word 
(with one inter-letter space). Sub-units are an important point of focus, because computerized optical recognition studies of Arabic handwriting have suggested that the sub-unit, rather than the word, is the basic unit of recognition (Belaid \& Choisy, 2008).

\section{The present study}

The present study provides a further exploration into the role of Arabic letter visibility as a possible cause of the optimal viewing position (OVP) effect. Bouma (1973) tested identification of the initial and final Latin letters of random letter strings (e.g., dvxmk) with the entire string presented to the left or right visual field. Nazir et al. (1992) measured the visibility of Latin letters embedded in a series of Xs. However, the letters did not appear at every possible position in the series, and fixation was only at the first or last letter in the series. Kajii and Osaka (2000) measured identification of letters embedded in digits, but once again, the entire string was presented to the left or right of a central fixation point (in their horizontal display condition). Finally, traditional studies of letter-in-string visibility (e.g., Estes, Allmeyer, \& Reder, 1976) used only central fixations. However, Stevens and Grainger (2003) provided a complete visibility matrix across fixation positions and letter-in-string positions for Latin letters. Thus, to date, there are no studies providing complete measures of isolated Arabic letter visibility across all combinations of fixation positions. Our study was designed to address this gap, while building on the classic work in this field in an attempt to highlight some key, unresolved issues. We used isolated connected and un-connected Arabic letters of different shapes (basic, initial, medial, and final) placed at central fixation (Experiment 1) and at various possible positions in a presentation (Experiment 2). In order to investigate whether performance on the visual identification task was modulated by letter type, we presented each of the isolated connected and un-connected letter targets in each of the eleven stimulus positions across the array to produce a mean RT (ms) for each letter type. Using an initial fixation paradigm enabled us to compare RTs with correctly identified letter targets appearing in different possible positions.

The present study assessed precisely what factors are at play during the computation of letter identities in the earliest phases of letter perception and whether this processing depends on centrally fixated (Experiment 1 ) and peripherally un-fixated (Experiment 2) vision. This was of special interest when the OVP paradigm was employed to investigate the Arabic language, with its unique visual features of connectedness (Table 1).

The processes used for identifying letters within letter strings are adaptive to the nature of the script to which the reader is exposed to during reading acquisition (Pitchford \& Lefgeway, 2008). One feature of an alphabetic orthography, such as Arabic, that may be extracted through a process of statistical learning is the 
frequency with which letters appear within words (i.e., how often a particular letter occurs in words, per se; Pitchford \& Lefgeway, 2008). Arabic connected letters are of higher frequency than un-connected letters occurring in words (AlMuhtaseb, Mahmoud, \& Qahwaji, 2009; Mahdi, 2010) (Appendix 1). In previous studies, significant negative correlations were found between the RT needed to detect a target letter and letter frequency. If letter frequency is an orthographic property that influences the identification of letters, RTs should be faster for identifying isolated connected target letters compared with isolated un-connected target letters that are least frequent in written words.

Furthermore, letters necessarily appear at different eccentricities. Thus, it is possible that part of the decline in visual or perceptual span performance will be attributed to changes in acuity with eccentricity.

However, this letter identification is unlikely to be due to a single process. We assume that one possible interpretation of the phenomenon is that it reflects the conjoint influence of three factors: (a) the drop in visual acuity as a function of distance from fixation, (b) the perceptual learning based on reading habits (Right - to - Left), and (c) the hemispheric lateralization. Because of the first factor, letter recognition becomes worse for letters that are farther from fixation. According to the second factor, recognition of letters presented to the left of fixation is better than letters presented to the right of fixation. Due to the second factor, recognition of letters presented to the right of fixation is better than letters presented to the left of fixation.

The hypotheses address the following: centrally-fixated and peripherallynon-fixated isolated connected/un-connected Arabic letters levels in isolation, at all eleven possible letter fixation locations. For the centrally-fixated isolated connected/un-connected Arabic letter level (Experiment 1), we addressed the following:

(1) Is readability affected by visual differentiations of the isolated connected $\backslash$ un-connected letterforms in Arabic? We expect that the isolated unconnected letters will be named faster than the isolated connected letters as the former have almost the same basic shape in every word position. Alternatively, the naming of isolated connected letters may be faster than the isolated un-connected letters because these letters are more frequent in words than isolated un-connected letters. This pattern supports a letter frequency effect of letter recognition.

(2) Is letter processing and recognition in Arabic dependent on letter shape (basic, initial, middle, or final)? We expect naming of medial letters to be the hardest as the medial letter shape is so different from the other shapes.

For the study questions related to the peripherally-non-fixated isolated connected/ un-connected Arabic letter level (Experiment 2), we addressed the following: 
(1) The same questions as above, but in the peripherally-non-fixated letter position.

(2) Is isolated connected/un-connected letter readability affected by visual eccentricity in Arabic? We expect that the recognition performance for letters will be a function of distance from fixation. Reaction times for letters will increase as a function of eccentricity. This pattern supports the visual acuity drop effect of letter recognition.

(3) Is isolated connected/un-connected letter readability affected by the visual field presentation in Arabic? We expect that recognition performance for isolated letters presented in the right visual field (RVF) projected to the left hemisphere (LH) will be better than for letters presented in the left visual field (LVF) projected to the right hemisphere (RH), because of the $\mathrm{LH}$ advantage in language processing. This pattern supports the hemispheric lateralization effect of letter recognition. Alternatively, the recognition performance for isolated letters presented in the LVF may be better than for isolated letters presented in the RVF according to the perceptual learning based on reading habits. Right-to-left-reading adults should be better at identifying letter within the central or left-to-central part of their visual field because that is where they have adapted to visualize words while learning to read.

\section{Experiment 1}

Experiment 1 addressed the influence of visual complexity of Arabic orthography on letter identification, specifically manipulating letter shape according to their connectedness type and position in a word. Thus, the goal of this experiment was to explore reading rates of isolated connected vs. un-connected letters in Arabic. A central fixation paradigm was used to present letters. The two types of isolated letters were presented in various shapes according to their position in a word (basic, initial, middle, and final). Participants were asked to read (recognize) each presented letter. The participant's performance was measured according to accuracy rates and RTs for each letter condition. The main experimental question was whether isolated Arabic letter processing and recognition is dependent on letter type (connected vs. un-connected) and/or shape (basic, initial, middle or final). This is the first experiment that has examined whether isolated letter identification is modulated by visual features of connected and unconnected Arabic letters and the resultant consequences for the higher order cognitive functioning needed for reading.

\section{Method}

Variables: The independent variables were isolated letter type (connected, un-connected) and isolated letter shape according to its position in a word (basic, initial, middle, and final). The dependent variables were accuracy rates and 
RTs for correct recognition. The experimental matrix was a within-subjects, bi-factorial $2 \times 4$ design.

Participants: A total of 24 university students participated in this experiment (average age $=22.5, \mathrm{SD}=2 ; 10$ males). All were native Arabic speakers, from middle socio-economic status, right-handed, displayed normal or corrected-tonormal vision in both eyes, and none had a history of neurological or emotional disorders. As university students, all participants are assumed to read at satisfactory levels; none was formally diagnosed as having reading impairments.

Stimuli: The stimuli were 2 lists of 22 isolated letters each according to letter type (connected, un-connected) and presented in all letter shapes according to its position in the word (basic, initial, middle, and final) (Table 1). The letters were in a white 24 Simplified Arabic Fix font on a black background displayed on a PC screen, presented randomly.

Procedure: A CRT display was placed at a viewing distance of $60 \mathrm{~cm}$ from the participant. There were 176 trials. Each trial contained the following steps:

(1) Two vertical fixation lines were presented in the middle of the screen for $300 \mathrm{~ms}$.

(2) The letter stimulus was presented for $150 \mathrm{~ms}$ with the letter that was to be fixated on placed between the lines (central fixation).

(3) The fixation lines remained on the screen until a voice key registered a response or until a time-out of 1,500 ms was reached (Figure 1). A break was provided after 30 trials or whenever the participant indicated that (s) he needed a break.

Figure 1. Time course of one trial in the letter central fixation task

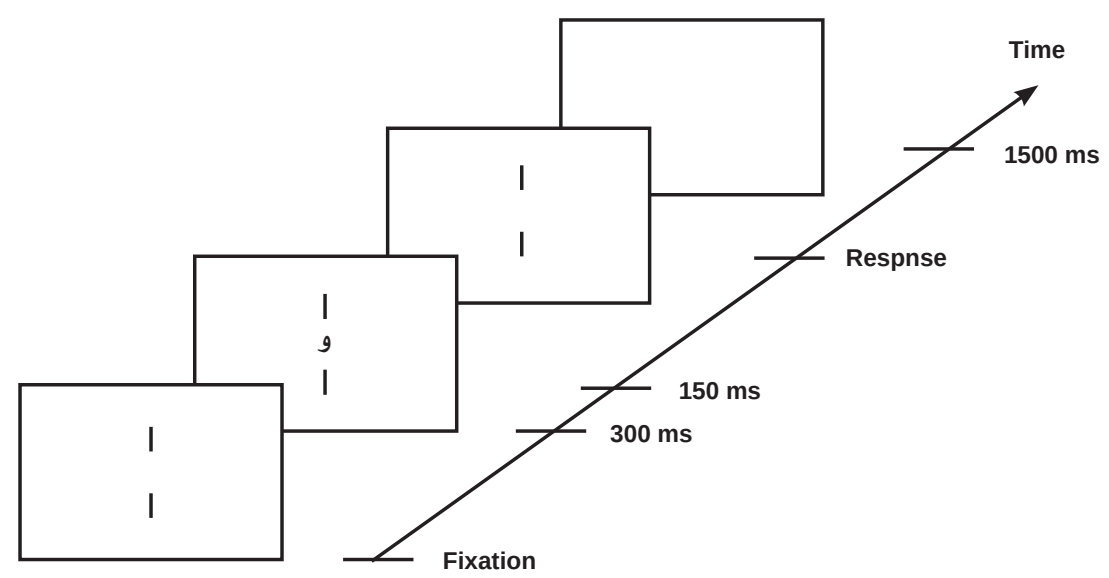


Participants received notice that there would be an Arabic letter between two vertical lines in the middle of the screen. The importance of fixating between the two lines, when these lines were presented, was stressed explicitly and repeatedly. Participants were asked to name the letters as quickly and as accurately as possible. Participants were informed that they could ask for a break whenever they wanted.

Each participant was tested individually with a random presentation sequence of the letters. The experimenter wrote the letter noted by the participant.

\section{Results}

Accuracy percentages exceeded $99 \%$ in all conditions; therefore, an accuracy analysis was not conducted. Differences in reading latencies between the two types of letters listed in the two lists, as a function of their shape and according to their word-position, (basic, initial, middle, and final) were analyzed with the repeated-measures analysis of variance (RM-ANOVA).

The effect of isolated letter type was significant $(\mathrm{F}(1,23)=5.76, \mathrm{p}<0.05)$. Reaction times for the connected letters (Mean $=409, \mathrm{SD}=99$ ) were shorter than for the un-connected letters (Mean $=430, S D=114$; see Figure 2, Table 2).

The effect of isolated letter shape according to its position in a word (basic, initial, middle, and final) was also significant $(\mathrm{F}(3,21)=3.12, \mathrm{p}<0.05)$. Reaction times for the medial position letter were identical to the final position letter but longer than for the basic and initial letter positions (see Figure 2, Table 2).

In addition, the interaction between letter type and position was not significant $(\mathrm{F}(3,21)=0.602, \mathrm{p}=0.621$; see Figure 2, Table 2).

Isolated letter readability was affected by visual differentiations of the connectedlun-connected letterforms in Arabic. As expected, the naming of isolated connected letters was faster than naming of isolated un-connected letters because these letters are visually more frequent in words than un-connected letters. This

Table 2. Reaction times as a function of isolated letter type (connected, un-connected) and isolated letter shape according to its position in a word (basic, initial, middle, and final)

Letter Shape According to its Position in a Word

Basic SD Initial SD Medial SD Final SD

\begin{tabular}{|c|c|c|c|c|c|c|c|c|c|}
\hline Letter & Connected & 395 & 96 & 400 & 84 & 419 & 100 & 419.2 & 117 \\
\hline Type & Un-connected & 415 & 112 & 420 & 112 & 435 & 117 & 436.2 & 117 \\
\hline
\end{tabular}


Figure 2. Reaction times as a function of isolated letter type (connected, un-connected) and isolated letter shape according to its position in a word (basic, initial, middle, and final). Note: Error bars represent standard error

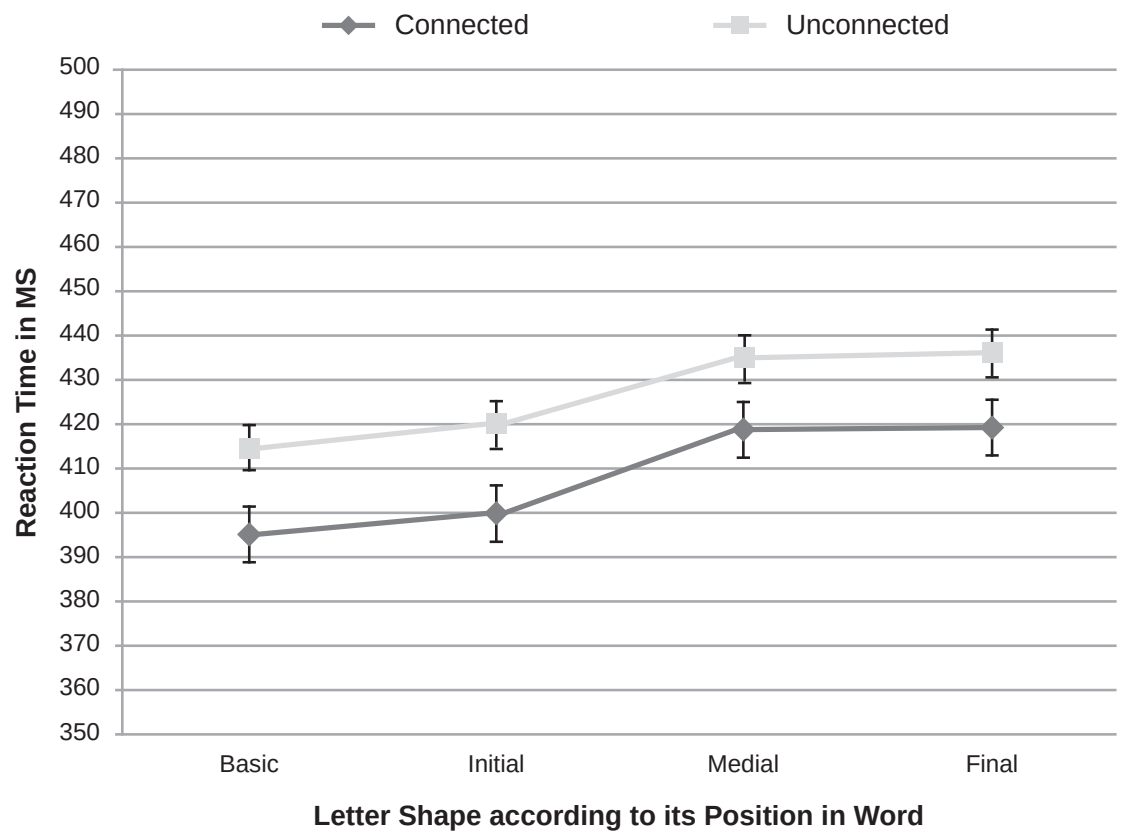

pattern supports a letter frequency effect of letter recognition, and is consistent with Abdelhadi, Ibrahim, \& Eviatar's (2011) finding that vowel detection in Arabic was better for letter strings containing connected letters than for those containing unconnected letters. In addition, isolated letter processing and recognition in Arabic depended on letter shape within a word. As expected, naming of medial and final letters was slower than basic and initial letters. It is worth to note that, although isolated un-connected letters were presented repeatedly (there are only 6 un-connected Arabic letters), possible reptetion effects can be discarded since it took a longer time to recognize them.

\section{Experiment 2}

The present experiment addressed the influence of visual complexity of Arabic orthography on letter identification OVP. Specifically, we assessed how isolated connected (or un-connected) letters presented in all possible left or right visual fields would affect isolated letter identification. Thus, the goal of this experiment was to explore the OVP of isolated connected vs. un-connected letters in Arabic. 
An initial fixation paradigm was used to present letters in the two visual fields (left, right) and all possible letter positions (1, 2, 3, 4, or 5; see Figure 3). The two types of letters were presented in various shapes according to their position in a word (basic, initial, middle, and final), the two visual fields (left, right), and all possible letter positions (1, 2, 3, 4, and 5). Participants were asked to read (recognize) each presented letter. Participant's performance was measured according to accuracy rates and RTs for each letter condition. The main experimental question was whether the OVP of isolated Arabic letters is dependent on letter type (connected, un-connected), shape (basic, initial, middle, or final), and visual field presentation (left, right). This is the first experiment that has assessed whether the OVP of Arabic letters is modulated by these factors and the consequences this has on the higher order cognitive functioning needed for reading.

\section{Method}

Variables: The independent variables were isolated letter type (connected, un-connected), letter shape according to its position in a word (basic, initial, middle, and final), visual field (left, right), and letter position (1, 2, 3, 4, and 5). The dependent variables were accuracy rates and RTs for correct recognitions. The experimental matrix was a within-subjects quadric-factorial $2 \times 4 \times 2 \times 5$ design.

Figure 3. Example of how isolated letter position was manipulated in the left visual field (LVF) and right visual field (RVF)

\begin{tabular}{|c|c|c|c|c|c|c|c|c|c|c|}
\hline \multicolumn{5}{|c|}{$\ll \quad$ LVF $\longrightarrow$} & \multirow[t]{2}{*}{+} & \multicolumn{5}{|c|}{$\ll \quad$ RVF $\longrightarrow$} \\
\hline & & & & & & & & & & \\
\hline & & & & & I & & & & & \\
\hline & & & & و & & و & & & & \\
\hline & & & & & I & & & & & \\
\hline & & & 9 & & & & 9 & & & \\
\hline & & & & & I & & & & & \\
\hline & & و & & & & & & 9 & & \\
\hline & & & & & I & & & & & \\
\hline & و & & & & & & & & 9 & \\
\hline & & & & & I & & & & & \\
\hline و & & & & & & & & & & 9 \\
\hline & & & & & I & & & & & \\
\hline 5 & 4 & 3 & 2 & 1 & + & 1 & 2 & 3 & 4 & 5 \\
\hline
\end{tabular}

Letter Position 
Participants: A total of 25 university students participated in the study (average age $=21.5, \mathrm{SD}=2 ; 10$ males). All were native Arabic speakers from medium socio-economic status, right-handed, displayed normal or corrected-to-normal vision in both eyes, and no history of neurological or emotional disorders. No participants were formally diagnosed as having reading impairments.

Stimuli: The stimuli included two new lists of 12 letters, each according to isolated letter type (connected, un-connected), letter shape according to its position in a word (basic, initial, middle, and final), visual field (left, right), and letter position (1, 2, 3, 4, and 5). The letters were in a white 24 Simplified Arabic Fix font on a black background displayed on a PC screen, presented randomly.

Procedure: The same procedure was used as in Experiment 1, except that stimuli were letters presented in all five initial letter fixation positions for each visual field and the total number of trials was 960 .

\section{Results}

Accuracy percentages exceeded $99 \%$ in all conditions; therefore, an accuracy analysis was not conducted. Differences in reading latencies between the two types of letters listed in the two lists according to their shape, position in a word (basic, initial, middle, and final), visual field (left, right), and letter position $(1,2,3,4$, and 5) were analyzed with the repeated-measures ANOVA.

The effect of isolated letter type (connected vs. un-connected) was significant $(\mathrm{F}(1,24)=8.67, \mathrm{p}<0.05)$. Reaction times for the isolated connected letters $(\mathrm{Mean}=408$, $\mathrm{SD}=109)$ were shorter than for the isolated un-connected letters (Mean $=426, \mathrm{SD}=107$ ).

The effect of isolated letter shape according to its position in a word (basic, initial, middle, and final) was significant $(\mathrm{F}(3,22)=24.25, \mathrm{p}<0.0001)$. Reaction times for the medial position letters were similar to the final position letters but longer than the basic and initial position letters.

The effect of visual field (left, right) was significant $(\mathrm{F}(1,24)=8.96, \mathrm{p}<0.006)$. Reaction times for letters presented in the right visual field were $(M e a n=408, S D=109)$ shorter than for letters presented in the left visual field (Mean $=426, \mathrm{SD}=107$ ).

The effect of letter position $(1,2,3,4$, and 5$)$ was also significant $(\mathrm{F}(4,21)=35.48$, $\mathrm{p}<0.0001)$. Reaction times for the letter increased as the letter position increased.

In addition, the interaction between letter type and position was not significant $(\mathrm{F}(3,21)=0.602, \mathrm{p}=0.621)$. All other interactions between the factors were also not significant (Table 3, Figure 4, Figure 5, Figure 6, Table 4).

Table 3. Reaction times as a function of isolated letter shape according to its position in a word (basic, initial, middle, and final)

Letter Shape According to its Position in a Word

\begin{tabular}{cccccccc}
\hline Basic & SD & Initial & SD & Medial & SD & Final & SD \\
405 & 106 & 410 & 103 & 427 & 112 & 427.7 & 111 \\
\hline
\end{tabular}


Figure 4. Reaction times as a function of isolated letter shape according to its position in a word (basic, initial, middle, and final). Note: Error bars represent standard error

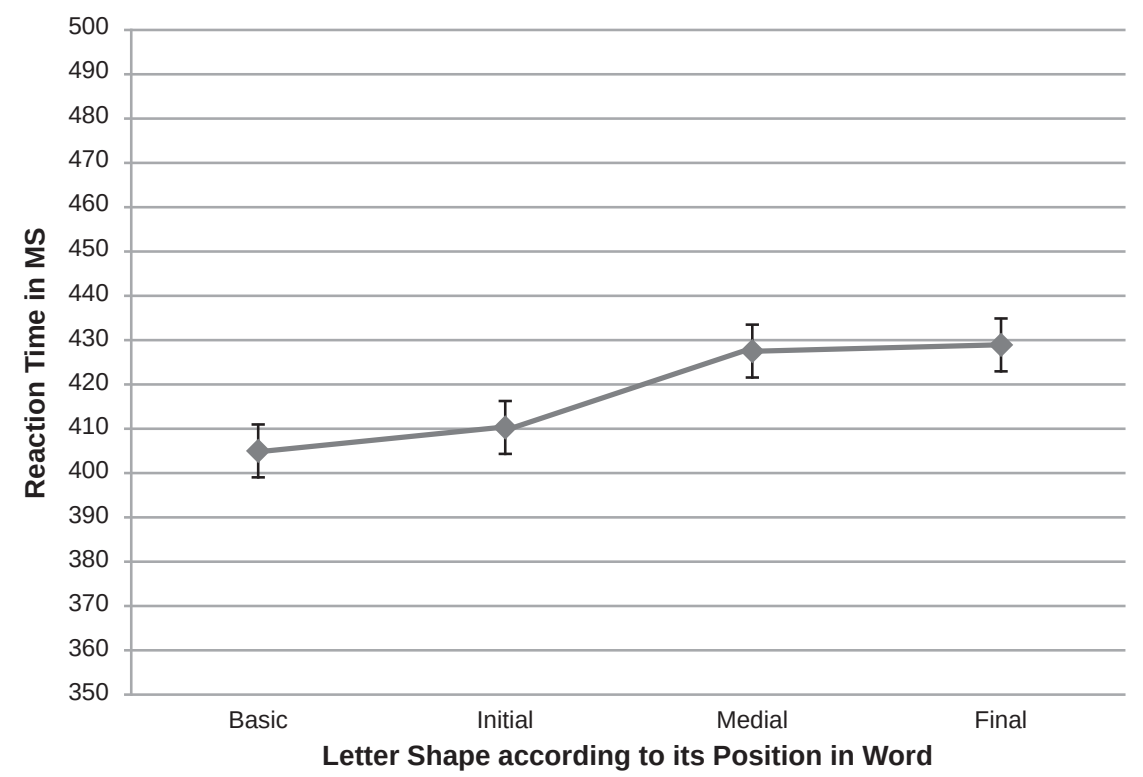

Figure 5. Reaction times of connected letters as a function of letter position (1, 2, 3, 4, and 5), letter shape according to its position in a word (basic, initial, middle, and final) and visual field (LVF, RVF). Note: Error bars represent standard error

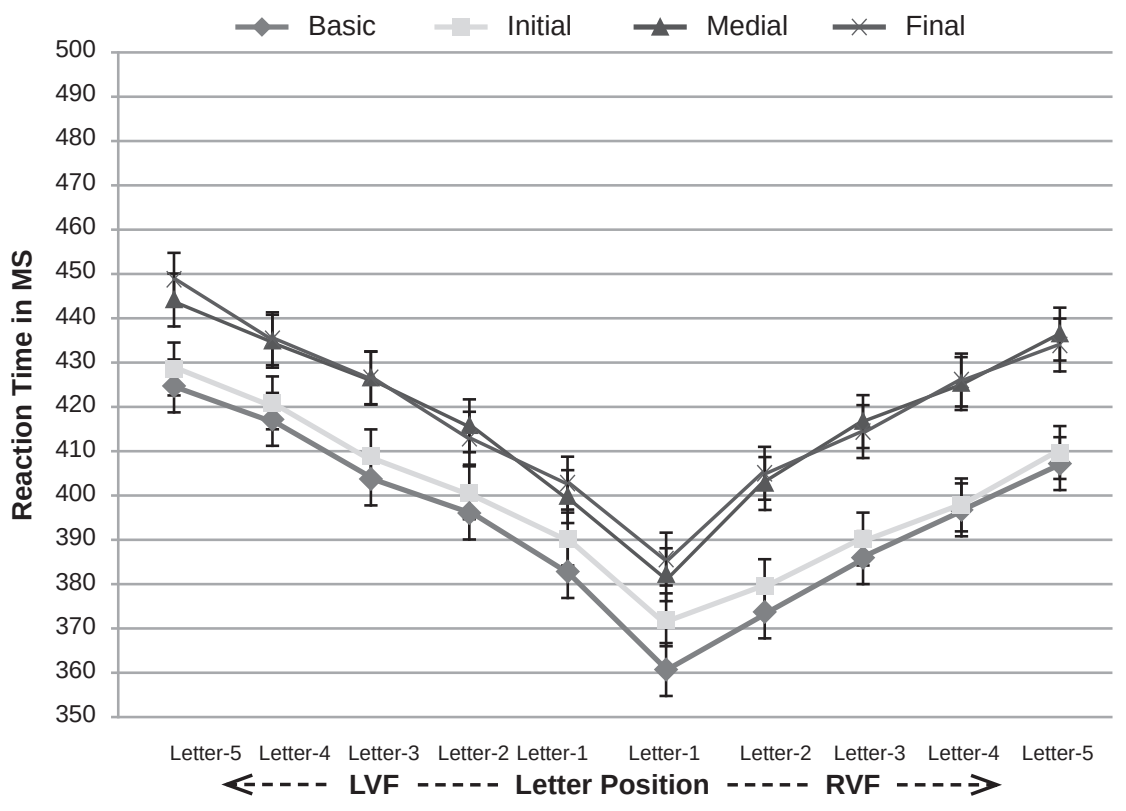


Figure 6. Reaction times of unconnected letters as a function of letter position $(1,2,3,4$, and 5), letter shape according to its position in a word (basic, initial, middle, and final) and visual field (LVF, RVF). Note: Error bars represent standard error

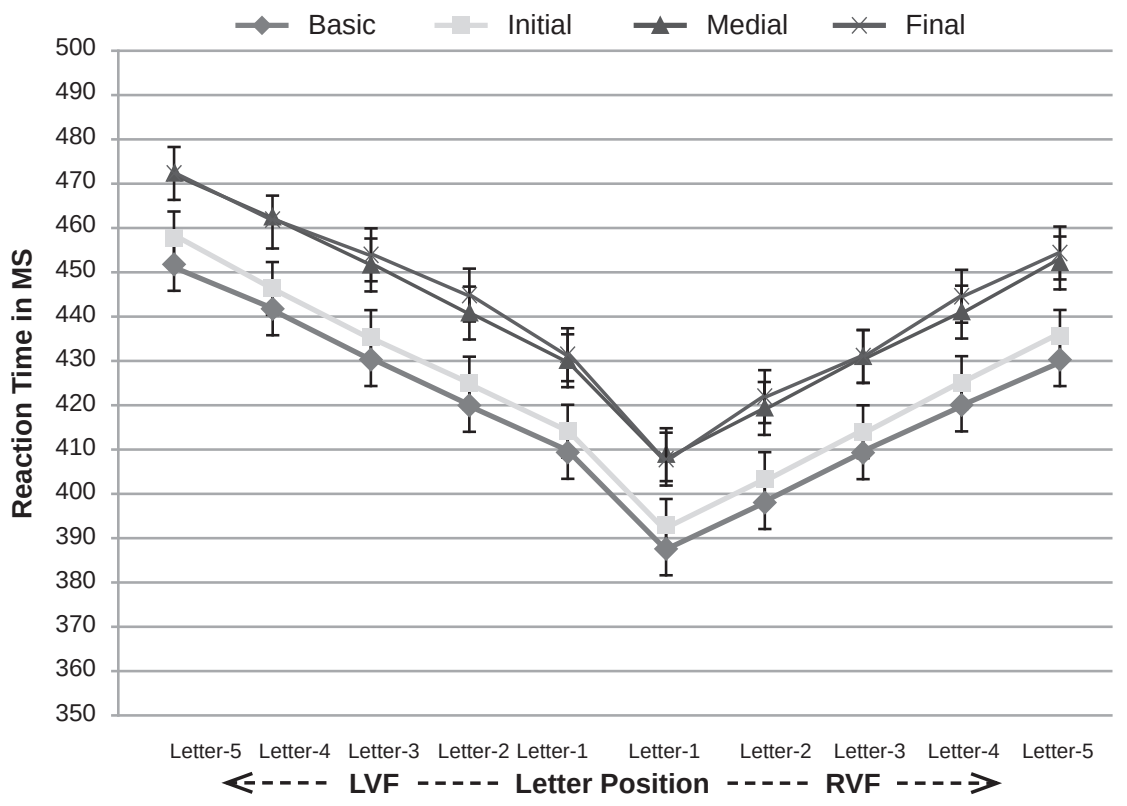

Table 4. Reaction times of connected and unconnected letters as a function of letter position (1, 2, 3, 4, and 5), letter shape according to its position in a word (basic, initial, middle, and final) and visual field (LVF, RVF)

\begin{tabular}{|c|c|c|c|c|c|c|c|c|c|c|c|c|c|c|c|c|c|c|c|c|}
\hline Connected & $\begin{array}{c}\text { Letter } \\
5\end{array}$ & $\mathrm{SD}$ & $\begin{array}{c}\text { Letter } \\
4\end{array}$ & SD & $\begin{array}{c}\text { Letter } \\
3\end{array}$ & SD & $\begin{array}{l}\text { Letter } \\
\quad 2\end{array}$ & SD & $\begin{array}{c}\text { Letter } \\
1\end{array}$ & $\mathrm{SD}$ & $\begin{array}{c}\text { Letter } \\
1\end{array}$ & $\mathrm{SD}$ & $\begin{array}{c}\text { Letter } \\
\quad 2\end{array}$ & SD & $\begin{array}{c}\text { Letter } \\
3\end{array}$ & SD & $\begin{array}{c}\text { Letter } \\
4\end{array}$ & SD & $\begin{array}{c}\text { Letter } \\
5\end{array}$ & SD \\
\hline Basic & 425 & 115 & 417 & 114 & 404 & 105 & 396 & 101 & 383 & 104 & 361 & 105 & 374 & 100 & 386 & 106 & 397 & 115 & 407 & 114 \\
\hline Initial & 429 & 113 & 421 & 115 & 409 & 106 & 401 & 100 & 390 & 102 & 372 & 104 & 380 & 99 & 390 & 107 & 398 & 113 & 410 & 113 \\
\hline Medial & 445 & 116 & 436 & 111 & 427 & 103 & 416 & 103 & 401 & 105 & 383 & 106 & 404 & 101 & 416 & 105 & 426 & 116 & 436 & 115 \\
\hline Final & 449 & 112 & 436 & 113 & 427 & 104 & 413 & 102 & 403 & 107 & 386 & 103 & 405 & 103 & 414 & 108 & 425 & 111 & 404 & 112 \\
\hline Unconnected & $\begin{array}{c}\text { Letter } \\
5\end{array}$ & $\mathrm{SD}$ & $\begin{array}{c}\text { Letter } \\
4\end{array}$ & SD & $\begin{array}{c}\text { Letter } \\
3\end{array}$ & $\mathrm{SD}$ & $\begin{array}{c}\text { Letter } \\
\quad 2\end{array}$ & SD & $\begin{array}{c}\text { Letter } \\
1\end{array}$ & $\mathrm{SD}$ & $\begin{array}{c}\text { Letter } \\
1\end{array}$ & $\mathrm{SD}$ & $\begin{array}{l}\text { Letter } \\
2\end{array}$ & SD & $\begin{array}{c}\text { Letter } \\
3\end{array}$ & SD & $\begin{array}{c}\text { Letter } \\
\quad 4\end{array}$ & SD & $\begin{array}{c}\text { Letter } \\
5\end{array}$ & $\mathrm{SD}$ \\
\hline Basic & 445 & 115 & 435 & 113 & 425 & 106 & 415 & 100 & 405 & 103 & 385 & 104 & 395 & 99 & 405 & 107 & 415 & 114 & 425 & 115 \\
\hline Initial & 450 & 114 & 440 & 116 & 430 & 105 & 420 & 101 & 410 & 103 & 390 & 105 & 400 & 101 & 410 & 106 & 420 & 114 & 430 & 112 \\
\hline Medial & 465 & 117 & 455 & 110 & 445 & 104 & 435 & 102 & 425 & 106 & 405 & 105 & 415 & 102 & 425 & 106 & 435 & 115 & 445 & 116 \\
\hline Final & 465 & 111 & 455 & 114 & 447 & 105 & 438 & 103 & 426 & 108 & 404 & 104 & 417 & 101 & 425 & 107 & 438 & 112 & 447 & 111 \\
\hline
\end{tabular}


The readability of isolated connected/un-connected letters was affected by visual eccentricity in Arabic. As expected, recognition performance for letters was dependent on the distance from fixation. Reaction times for letters increased as a function of eccentricity. This pattern supports the visual acuity drop effect of letter recognition. In addition, readability of isolated connected/ un-connected letters was affected by visual field presentation. As expected, recognition performance for letters presented in the right visual field (RVF) was better than for letters presented in the left visual field (LVF). This pattern supports the hemispheric lateralization effect of letter recognition and disapproves the perceptual learning explanation based on reading habits. However, the effect of isolated connected/un-connected letter position by visual eccentricity in Arabic was identical in RVF and LVF.

\section{General discussion}

The present study explored in Experiment 1 how the visual complexity of Arabic orthography affects letter identification, according to their connectedness type (connected vs. un-connected) and position in a word (basic, initial, middle, and final). The main finding of Experiment 1 was that isolated letter readability was affected by visual differentiations of the connected lun-connected letterforms in Arabic. The naming of isolated connected letters was faster than naming of isolated un-connected letters because these letters are visually more frequent in words than un-connected letters. This pattern supports a letter frequency effect of letter recognition. In addition, isolated letter processing and recognition in Arabic depended on letter shape within a word since the naming of medial and final letters was slower than basic and initial letters.

In Experiment 2 the present study explored how initial viewing position affects the processing of isolated Arabic letters. In Experiment 2, we systematically manipulated the initial letter viewing position by shifting letters horizontally relative to an imposed initial viewing position. Variations in recognition and processing time were measured as a function of initial viewing position. The critical finding from Experiment 2 was a symmetric drop-off in average isolated letter visibility as the initial fixation position moved from the center of the stimulus to the periphery. This experiment replicated the well-known distance-from-fixation effects for isolated Latin letter identification (e.g., Estes et al., 1976; Nazir, Deutsch, Grainger, \& Frost, 2000; Nazir et al., 1992). Recognition performance was mostly a function of distance from fixation. The shape of the isolated letter visibility function varied substantially across the different fixation positions. There was one pattern of isolated letter visibility that emerged as fixation position varied. Fixations on the central letter produced a visibility curve in which the fixated letter was recognized most easily, with a monotonic decline in performance for letters further along the string. When the middle of an eleven-letter string was 
fixated upon, visibility was greatest for the fixated letter and dropped monotonically for letters further from fixation (Stevens \& Grainger, 2003). Visual acuity limitations may explain the OVP effect. Previous research has argued that the decrease in visual acuity with retinal eccentricity contributes to the OVP effects of word recognition; this occurs because visual acuity decreases with greater letter distance from the fixation position, resulting in a loss of visual information (Brysbaert \& Nazir, 2005; Nazir, 1991; Rayner, 2009; Vitu, Lancelin, \& d'Unienville, 2007). It seems that the OVP effect is more evident in extrafoveal locations, with no OVP effects observed for foveal locations (Almabruk, Paterson, McGowan, \& Jordan, 2011; Liu \& Li, 2013).

In addition, results from Experiment 2 appear to conform to prior reports of higher levels of isolated Latin letter visibility in the right visual field (Bouma, 1973; Kajii \& Osaka, 2000; Nazir et al., 1992). Having the isolated Arabic letters presented within different letter positions (11 letter positions) induced a specific processing bias that gave rise to superior visibility for isolated letters presented in the right visual field (RVF) compared to the left visual field (LVF). However, the effect of isolated connected/un-connected letter position by visual eccentricity in Arabic was identical in RVF and LVF.

It is interesting to note that Nazir et al. (2000), in their study of Hebrew (a language read from right to left as Arabic), found that letters to the right of a fixation were identified better than letters to the left of a fixation.

Perceptual learning based on reading habits (Brysbaert \& Nazir, 2005; Deutsch \& Rayner, 1999; Farid \& Grainger, 1996; Nazir et al., 2004; Wong \& Hsiao, 2012) does not account for the letter recognition OVP effect observed in this study. Because Arabic is read from right to left, letters are repeatedly recognized in the same location in the visual field. As a result, letter recognition is more effective when the initial fixation occurs at the position that readers most often fixate on while reading (Brysbaert \& Nazir, 2005; Ducrot \& Pynte, 2002). According to the reading habit hypothesis, the leftward asymmetry of the initial fixation curve is due to the increased average visibility of letters to the right of the fixation position (compared to letters to the left of the fixation position). This asymmetry in letter visibility is typically attributed to the influence of reading habits on the deployment of attention, with a rightward bias induced in languages that are read from left to right. Therefore, this hypothesis incorrectly predicted that the Arabic initial fixation curve would be asymmetric to the right. This hypothesis was based on the assumption that because of a leftward bias in the deployment of attention (in a language that is read from right to left) letters would be more visible to the left of the fixation position.

Prior research on left-to-right languages such as English, French, and German has shown a systematic leftward asymmetry in OVP. According to the hemispheric specialization hypothesis, the leftward asymmetry is because leftward fixations leave more of the word in the right visual field. This leads information 
extracted from a greater proportion of the word to be directly transmitted to the left hemisphere, where the principal neural structures subtending visual word recognition are located. This hypothesis correctly predicted that a leftward asymmetry should also be observed in Arabic, since speakers of Arabic presumably also have language structures lateralized in the left hemisphere. According to this view, all information to the left of the fixation position will project unilaterally to the right hemisphere (RH), at least during initial processing, and all information to the right of the fixation will project unilaterally to the left hemisphere (LH). Since it has been established that the $\mathrm{LH}$ generally has superior language processing capabilities to the RH (Almabruk et al., 2011), this putative division in hemispheric processing at the point of fixation has been claimed to have important effects on language processing (Ellis \& Brysbaert, 2010). In particular, information projected separately to each hemisphere from each side of the fixation position is integrated in the language-dominant LH (for the majority of individuals) via interhemispheric transfer prior to lexical processing (e.g., Brysbaert, 1994, 2004; Brysbaert \& Nazir, 2005; Hunter et al., 2007; van der Haegen et al., 2010). Thus, when a letters falls to the right of the fixation position it creates a perceptual advantage because this letter project directly to the LH, with less information having to undergo disruptive interhemispheric transfer prior to recognition. The results of our experiments showed RVF advantage for isolated letter recognition.

Moreover, like Latinate languages, Arabic produces perceptual superiority for linguistic stimuli (letters, words) displayed to the right of the fixation position, indicating classic LH dominance for processing words (Ibrahim \& Eviatar, 2009).

Such findings support the established view that states the LH specializes in linguistic processing for alphabetic languages; it also provides further evidence that a LH advantage also occurs for languages that are read from right to left, such as Arabic (Ibrahim \& Eviatar, 2009).

Since sensitivity to statistical regularities of visual orthographic input emerges as a product of learning to read, effects of letter frequency were also observed in the performance of skilled readers on a low-level task. However, this does not explicitly activate lexical representations such as visual letter recognition or identification; this does assume that these tasks tap into the written word recognition system (Pitchford \& Lefgeway, 2008). Since using letter strings instead of real words in tasks investigating letter identification minimizes the effects of top-down processes, the advantage of recognizing isolated connected Arabic letter types compared with isolated un-connected letter types would suggest that this effect operates at, or modulates, a relatively early stage of visual orthographic processing (e.g., abstract letter encoding). Additionally, medial and final letterforms required greater reading time than basic and initial letterforms.

These results indicate that it might be possible to standardize reading rates across the visual field by compensating for reduced acuity and eccentric position to better equate the visibility of letters within words. 
The results of this study have important implications for current theories on encoding letter identity within written word recognition. Several specific, yet contrasting, models of letter position encoding have been proposed in recent years (see Davis, 2006; Schoonbaert \& Grainger, 2004, for a detailed review). In some respects, our findings are most consistent with serial models of letter position encoding (e.g. Whitney, 2001). However, to be considered suitable for Arabic, models of isolated letter recognition should take into account the present findings. This may involve modifying models such that the models incorporate: (i) the type of isolated letters (connected, un-connected) by which processing Arabic orthography would benefit identification of connected letters, and (ii) the shape of isolated letters (basic, initial, medial, and final).

\section{Summary and conclusions}

The visual isolated letter recognition is influenced by: (i) the isolated letters' type (connected, un-connected), as connected letters are easier to recognize than un-connected letters; (ii) letters' shape (basic, initial, medial, final), as medial and final are harder to recognize than basic and initial letter shapes; (iii) visual field, as reading rates were longer for letter stimuli that have been presented in LVF compared to RVF; and (iv) eccentricity, as isolated letter reading rates were correlated with its eccentric placement across the possible letter positions.

We argue that the most parsimonious account of the complete set of findings is in terms of visual Arabic letters connectedness, visual acuity, plus hemispheric lateralization. Practically, these results indicate that it might be possible to standardize reading rates across the visual field by compensating for reduced acuity and eccentric position to better equate the visibility of letters within words. Theoretically, the results of this study have important implications for current theories on encoding letter identity within written word recognition. However, since there are universal processes in reading and writing-system specific processes (Perfetti, Cao, \& Booth, 2013), in the letter level our findings are most consistent with serial models of letter position encoding (e.g. Whitney, 2001), while in the word level our findings are most consistent with the dual route model.

Interestingly, based on the data of Experiment 2, it could have been expected that the initial letter form would be named faster when it appeared at the beginning of the letter string. The same goes for the medial form and medial positions, and the final form and final position. The fact that there was no interaction between form and position in the string indicates that participants were not hindered by an incongruency between form and position in the string. This finding would suggest that participants rely on abstract letter representations, regardless of case (lowercase/uppercase for the Roman alphabet) or letter position (isolated/initial/middle/final for the Arabic alphabet). The present data are consistent with the findings obtained by Kinoshita and Kaplan (2008) with the 
Roman alphabet in a cross-case letter match task (i.e., similar priming for a-A and $\mathrm{c}-\mathrm{C}$ ). Likewise, the present data are also consistent with previous findings obtained by Kinoshita and Norris (2009) using the masked priming same-different task with English words. These data support the view that priming of abstract letter representations is a universal phenomenon.

Recent studies (Carreiras, Perea, \& Abu Mallouh, 2012; Carreiras, Perea, Gil-López, Abu Mallouh, \& Salillas, 2013) have examined whether priming of abstract letter identities takes place in Arabic-an orthographic system in which letter shape varies according to letter position and is also modulated by the connectivity patterns of the neighboring letters. The magnitudes of masked repetition priming were equivalent for visually similar and for visually dissimilar letters in their middle and isolated forms, thus demonstrating that priming of abstract letter identities does occur in Arabic.

In Latin alphabet, Forster (1998, p. 221) noticed that cAsE aLtErNaTiOn does not affect the masked priming effect, whereas it usually slows down target processing. In addition, Rayner, McConkie, and Zola (1980) found no difference in reading speed when participants saw the upcoming words in parafoveal vision in the same case as when they saw them later in foveal vision or in a different case. Petit, Midgley, Holcomb, and Grainger (2006) have found also that priming effects are practically as strong for visually dissimilar lower- and uppercase versions of a given letter (e.g., g-G) as they are with more similar combinations (e.g., c-C), and this is true even when the prime is formed from parts of the opposite-case version of the target letter, such as midsegments (Petit \& Grainger, 2002). Similarly, Brysbaert, Speybroeck, and Vanderelst (2009) found that the priming of the acronyms did not depend on the letter case in which they were presented. These results have been taken as evidence for the existence of abstract letter representations (Dufor \& Rapp, 2013) that disregard letter shape information (Arguin \& Bub, 1995).

Finally, the present experiments suggest that a systematic study of visual features and OVP of isolated letters in Arabic read from right to left provides an appropriate means of testing our hypotheses. The results from the present experiments indicate that the reading habit hypothesis is lacking, while the hemispheric lateralization and letter visibility hypotheses merit further elaboration and testing.

\section{References}

Abdelhadi, S., Ibrahim, R., \& Eviatar, Z. (2011). Perceptual load in the reading of Arabic: Effects of orthographic visual complexity on detection. Writing Systems Research, 3 (2), 117-127.

Abd El-Minem, F.M. (1987). Elm al-sarf. Jerusalem: Al-Taufik Press [in Arabic]. Abu-Rabia, S. (2001). The role of vowels in reading Semitic scripts: Data from Arabic and Hebrew. Reading and Writing: An Interdisciplinary fournal, $14(1-2), 39-59$. 
Adelman, J.S., Marquis, S.J., \& Sabatos-DeVito, M.G. (2010). Letters in words are read simultaneously, not in left-to-right sequence. Psychological Science, 21 (12), 1799-1801.

Almabruk, A.A.A., Paterson, K.B., McGowan, V.A., \& Jordan, T.R. (2011). Evaluating effects of divided hemispheric processing on word recognition in foveal and extrafoveal displays: The evidence from Arabic. PLoS ONE, 6 (4): e18131. Al-Muhtaseb, H., Mahmoud, S., \& Qahwaji, R. (2009). A novel minimal script for Arabic text recognition databases and benchmarks. International fournal of Circuits, Systems and Signal Processing, 3 (3), 145-153.

Arguin, M. \& Bub, D. (1995). Priming and response selection processes in letter classification and identification tasks. Fournal of Experimental Psychology: Human Perception and Performance, 21 (5), 1199-1219.

Averbach, E. \& Coriell, A.S. (1961). Short-term memory in vision. Bell Labs Technical fournal, 40 (1), 309-328.

Belaid, A. \& Choisy C. (2008). Human Reading Based Strategies for Off-Line Arabic Word Recognition. Arabic and Chinese Handwriting Recognition Lecture Notes in Computer Science, 4768, 36-56.

Bouma, H. (1973). Visual interference in the parafoveal recognition of initial and final letters of words. Vision Research, 13 (4), 767-782.

Brysbaert, M. (1994). Interhemispheric transfer and the processing of foveally presented stimuli. Behavioral Brain Research, 64 (1-2), 151-161.

Brysbaert, M. (2004). The importance of interhemispheric transfer for foveal vision: A factor that has been overlooked in theories of visual word recognition and object perception. Brain and Language, 88 (3), 259-267.

Brysbaert, M. \& Nazir, T.A. (2005). Visual constraints in written word recognition: Evidence from the optimal viewing-position effect. Fournal of Research in Reading, 28 (3), 216-228.

Brysbaert, M., Speybroeck, S., \& Vanderelst, D. (2009) Is there room for the BBC in the mental lexicon? On the recognition of acronyms. The Quarterly fournal of Experimental Psychology, 62 (9), 1832-1842.

Brysbaert, M., Vitu, F., \& Schroyens, W. (1996). The right visual field advantage and the optimal viewing position effect: On the relation between foveal and parafoveal word recognition. Neuropsychology, 10 (3), 385-395.

Butler, B.E. (1975). Selective attention and target search with brief visual displays. The Quarterly fournal of Experimental Psychology, 27 (3), 467-477.

Butler, B.E. \& Merikle, P.M. (1973). Selective masking and processing strategy. The Quarterly fournal of Experimental Psychology, 25 (4), 542-548.

Carrasco, M., Kinchla, R.A., \& Figueroa, J.G. (1988). Visual letter-matching and the time course of visual and acoustic codes. Acta Psychologica, 69 (1), 1-17.

Carreiras, M., Perea, M., \& Abu Mallouh, R. (2012). Priming of abstract letter representations may be universal: The case of Arabic. Psychonomic Bulletin and Review, 19 (4), 685-690. 
Carreiras, M., Perea, M., Gil-López, C., Mallouh, R.A., \& Salillas, E. (2013). Neural correlates of visual versus abstract letter processing in Roman and Arabic scripts. Fournal of Cognitive Neuroscience, 25 (11), 1975-1985.

Chung, S.T.L., Legge, G.E., \& Cheung, S.H. (2004). Letter-recognition and reading speed in peripheral vision benefit from perceptual learning. Vision Research, 44 (7), 695-709.

Davis, C.J. (2006). Orthographic input coding: A review of behavioural data and current models. In S. Andrews (Ed.), From Inkmarks to Ideas: Current Issues in Lexical Processing (pp. 180-206). Hove: Psychology Press.

Deutsch, A. \& Rayner, K. (1999). Initial fixation location effects in reading Hebrew words. Language and Cognitive Processes, 14 (4), 393-421.

Ducrot, S. \& Pynte, J. (2002). What determines the eyes' landing position in words? Perception \& Psychophysics, 64 (7), 1130-1144.

Dufor, O. \& Rapp, B. (2013). Letter representations in writing: an fMRI adaptation approach. Frontiers in Psychology, 4 (781), 1-14.

Ellis, A.W. \& Brysbaert, M. (2010). Split fovea theory and the role of the two cerebral hemispheres in reading: A review of the evidence. Neuropsychologia, 48 (2), 353-365.

Estes, W.K., Allmeyer, D.H., \& Reder, S.M. (1976). Serial position functions for letter identification at brief and extended exposure durations. Perception \& Psychophysics, 19(1), 1-15.

Falkenberg, H.K., Rubin, G.S., \& Bex, P.J. (2007) Acuity, crowding, reading and fixation stability. Vision Research, 47 (1), 126-135.

Farid, M. \& Grainger, J. (1996). How initial fixation position influences visual word recognition: A comparison of French and Arabic. Brain and Language, 53 (3), 351-368.

Finkbeiner, M. \& Coltheart, M. (2009). Letter recognition: from perception to representation. Cognitive Neuropsychology, 26 (1), 1-6.

Forster, K.I. (1998). The pros and cons of masked priming. fournal of Psycholinguistic Research, 27 (2), 203-233.

Geyer, L.H. \& DeWald, C.G. (1973). Feature lists and confusion matrices. Perception \& Psychophysics, 14 (3), 471-482.

Gibson, E.J. (1969). Principles of Perceptual Learning and Development. New York: Appleton-Century-Crofts.

Grainger, J. (2008). Cracking the orthographic code: An introduction. Language and Cognitive Processes, 23 (1), 1-35.

Grainger, J., Granier, J.P., Farioli, F., Van Assche, E., \& van Heuven, W.J. (2006). Letter position information and printed word perception: The relative-position priming constraint. Journal of Experimental Psychology: Human Perception and Performance, 32 (4), 865-884.

Grainger, J. \& Jacobs, A.M. (1996). Orthographic processing in visual word recognition: A multiple read-out model. Psychological Review, 103 (3), 518-565. 
Grainger, J., Rey, A., \& Dufau, S. (2008). Letter perception: from pixels to pandemonium. Trends in Cognitive Sciences, 12 (10), 381-387.

Grainger, J. \& van Heuven, W. (2003). Modeling letter position coding in printed word perception. In P. Bonin (Ed.), The Mental Lexicon (pp. 1-24). New York: Nova Science.

Haber, R. N., \& Standing, L. (1969). Location of errors with a poststimulus indicator. Psychonomic Science, 17 (6), 345-346.

Hunter, Z.R., Brysbaert, M., \& Knecht, S. (2007). Foveal word reading requires interhemispheric communication. Fournal of Cognitive Neuroscience, 19(8), 1373-1387.

Ibrahim, R. \& Eviatar, Z. (2009). Language status and hemispheric involvement in reading: Evidence from trilingual Arabic speakers tested in Arabic, Hebrew, and English. Neuropsychology, 23 (2), 240-254.

Jacobs, A.M., Nazir, T.A., \& Heller, O. (1989). Perception of lowercase letters in peripheral vision: A letter discrimination matrix based on saccade latencies. Perception \& Psychophysics, 46 (1), 95-102.

Jordan, T.R. \& Paterson, K.B. (2009). Re-evaluating split-fovea processing in word recognition: A critical assessment of recent research. Neuropsychologia, 47 (12), 2341-2353.

Kajii, N. \& Osaka, N. (2000). Optimal viewing position in vertically and horizontally presented Japanese words. Perception \& Psychophysics, 62 (6), 1634-1644.

Keren, G. \& Baggen, S. (1981). Recognition models of alphanumeric characters. Perception \& Psychophysics, 29 (3), 234-246.

Kinoshita, S. \& Kaplan, L. (2008). Priming of abstract letter identities in the letter match task. The Quarterly Journal of Experimental Psychology, 61 (12), 1873-1885.

Kinoshita, S. \& Norris, D. (2009). Transposed-letter priming of pre-lexical orthographic representations. Fournal of Experimental Psychology: Learning, Memory \& Cognition, 35 (1), 1-18.

Lavidor, M., Ellis, A., Shillcock, R., \& Bland, T. (2001). Evaluating a split processing model of visual word recognition: Effects of word length. Cognitive Brain Research, 12 (2), 265-272.

Lavidor, M., \& Walsh, V. (2004). Opinion - The nature of foveal representation. Nature Reviews Neuroscience, 5 (9), 729-735.

Legge, G.E., Mansfield, J.S., \& Chung, S.T.L. (2001). Psychophysics of reading: XX. Linking letter recognition to reading speed in central and peripheral vision. Vision Research, 41 (6), 725-743.

Legein, C.H. \& Bouma, H. (1977). Dyslectic and normally-reading children. I. Exploration of a letter-search test for screening purposes. II. Follow-up and further exploration in 4 weak and 4 normal readers on letter, word and number recognition. Documenta Ophthalmologica, 42 (2), 391-396.

Lindell, A.K. \& Nicholls, M.E.R. (2003). Cortical representation of the fovea: Implications for visual half-field research. Cortex, 39 (1), 111-117. 
Liu, P. \& Li, X. (2013). Optimal viewing position effects in the processing of isolated Chinese words.Vision Research, 81, 45-57

Mahdi, M. (2010). A study of Arabic letter frequency analysis. http://www.intellaren.com/articles/en/a-study-of-arabic-letter-frequency-analysis. Accessed 4 June 2015.

Martin, C.D., Thierry, G., Démonet, J.F., Roberts, M., \& Nazir, T. (2007). ERP evidence for the split fovea theory. Brain Research, 1185, 212-220.

Marzouki, Y., Meeter, M., \& Grainger, J. (2013). Location invariance in masked repetition priming of letters and words. Acta Psychologica, 142 (1), 23-29.

McClelland, J.L. \& Rumelhart, D.E. (1981). An interactive activation model of context effect in letter perception. Part I: An account of basic findings. Psychological review, 88 (5), 375-407.

Merikle, P.M., Coltheart, M., \& Lowe, D.G. (1971). On the selective effects of a patterned masking stimulus. Canadian fournal of Experimental Psychology, 25 (3), 264-279.

Merikle, P.M., Lowe, D.G., \& Coltheart, M. (1971). Familiarity and method of report as determinants of tachistoscopic performance. Canadian fournal of Experimental Psychology, 25 (2), 167-174.

Mewhort, D.J.K. \& Campbell, A.J. (1978). Processing spatial information and the selective-masking effect. Perception \& Psychophysics, 24 (1), 93-101.

Miller, P. \& Vaknin, V. (2012). The involvement of letter names in the silent processing of isolated letters: A developmental Perspective. Memory \& Cognition, 40 (8), 1276-1288.

Miozzo, M. \& Caramazza, A. (1998). The varieties of pure alexia: The case of failure to access graphemic representations. Cognitive Neuropsychology, 15(1-2), 203-238.

Mycroft, R., Hanley, J.R., \& Kay, J. (2002). Preserved access to abstract letter identities despite abolished letter naming in a case of pure alexia. Fournal of Neurolinguisitcs, 15 (2), 99-108.

Nazir, T.A. (1991). On the role of refixations in letter strings: The influence of oculomotor factors. Perception \& Psychophysics, 49 (4), 373-389.

Nazir, T.A., Ben-Boutayab, N., Decoppet, N., Deutsch, A., \& Frost, R. (2004). Reading habits, perceptual learning, and recognition of printed words. Brain and Language, 88 (3), 294-311.

Nazir, T.A., Deutsch, A., Grainger, J., \& Frost, R. (2000). The role of early perceptual learning in reading. Abstracts of the Psychonomic Society, 5, 83.

Nazir, T.A., Heller, D., \& Sussmann, C. (1992). Letter visibility and word recognition: The optimal viewing position in printed words. Perception \& Psychophysics, 52 (3), 315-328.

Nazir, T.A., Jacobs, A.M., \& O'Regan, J.K. (1998). Letter legibility and visual word recognition. Memory \& Cognition, 26 (4), 810-821.

Paterson, K.B., Jordan, T.R., \& Kurtev, S. (2009). Binocular Fixation Disparity in Single Word Displays. Journal of Experimental Psychology: Human Perception and Performance, 35 (6), 1961-1968. 
Pelli, D.G., Burns, C.W., Farrell, B., \& Moore-Page, D.C. (2006). Feature detection and letter identification. Vision Research, 46 (28), 4646-4674.

Perfetti, C.A., Cao, F., \& Booth, J.R. (2013). Specialization and universals in the development of reading skill: How Chinese research informs a universal science of reading. Scientific Studies of Reading, 17 (1), 5-21.

Petit, J.-P. \& Grainger, J. (2002). Masked partial priming of letter perception. Visual Cognition, 9 (3), 337-353.

Petit, J.-P., Midgley, K.J., Holcomb, P.J., \& Grainger, J. (2006). On the time course of letter perception: A masked priming ERP investigation. Psychonomic Bulletin \& Review, 13 (4), 674-681.

Pitchford, N.J., Ledgeway, T., \& Masterson, J. (2008). Effect of orthographic processes on letter position encoding. Fournal of Research in Reading, 31 (1), 97-116.

Posner, M.I. \& Mitchell, R.F. (1967). Chronometric analysis of classification. Psychological Review, 74 (5), 392-409.

Rayner, K. (2009). Eye movements and attention in reading, scene perception, and visual search. The Quarterly fournal of Experimental Psychology, 62 (8), 1457-1506.

Rayner, K., McConkie, G.W., \& Zola, D. (1980). Integrating information across eye movements. Cognitive Psychology, 12 (2), 206-226.

Reilhac, C., Jucla, M., Iannuzzi, S., Valdois, S., \& Démonet, J.-F. (2012). Effect of orthographic processes on letter identity and letter-position encoding in dyslexic children. Frontiers in Psychology, 3 (154), 1-11.

Shillcock, R., Ellison, T.M., \& Monaghan, P. (2000). Eye-fixation behavior, lexical storage, and visual word recognition in a split processing model. Psychological Review, 107 (4), 824-851.

Schoonbaert, S. \& Grainger, J. (2004). Letter position coding in printed word perception: Effects of repeated and transposed letters. Language and Cognitive Processes, 19 (3), 333-367.

Schwantes, F.M. (1978). Stimulus position functions in tachistoscopic identification tasks: Scanning, rehearsal, and order of report. Perception \& Psychophysics, 23 (3), 219-226.

Selfridge, O.G. \& Neisser, U. (1960). Pattern recognition by machine. Scientific American, 20, 60-68.

Selfridge, O.G. (1959). Pandemonium: A paradigm for learning. In D.V. Blake \& A.M. Uttley (Eds.), Proceedings of the Symposium on Mechanisation of Thought Processes (pp. 511-529). London: H. M. Stationary Office.

Solomon, J.A. \& Pelli, D.G. (1994). The visual filter mediating letter identification. Nature, 369 (6479), 395-397.

Stevens, M. \& Grainger, J. (2003). Letter visibility and the viewing position effect in visual word recognition. Perception \& Psychophysics, 65 (1), 133-151.

Taouk, M. \& Coltheart, M. (2004). The cognitive processes involved in learning to read in Arabic. Reading and Writing, 17 (1-2), 27-57. 
Tydgat, I. \& Grainger, J. (2009). Serial position effects in the identification of letters, digits, and symbols. Journal of Experimental Psychology: Human Perception and Performance, 35 (2), 480-498.

Van der Haegen, L. \& Brysbaert, M. (2011). The mechanisms underlying the interhemispheric integration of information in foveal word recognition: Evidence for transcortical inhibition. Brain and Language, 118 (3), 81-89.

Van der Haegen, L., Drieghe, D., \& Brysbaert, M. (2010). The split fovea theory and the leicester critique: What do the data say? Neuropsychologia, 48 (1), 96-106.

Vitu, F., Lancelin, D., \& d'Unienville, V.M. (2007). A perceptual-economy account for the inverted-optimal viewing position effect. Fournal of Experimental Psychology: Human Perception and Performance, 33 (5), 1220-1249.

Whitney, C. (2001). How the brain encodes the order of letters in a printed word: The SERIOL model and selective literature review. Psychonomic Bulletin \& Review, 8(2), 221-243.

Wolford, G. \& Hollingsworth, S. (1974). Retinal location and string position as important variables in visual information processing. Perception \& Psychophysics, 16 (3), 437-442.

Wong, Y.K. \& Hsiao, J.H. (2012). Reading direction is sufficient to account for the optimal viewing position in reading: The case of music reading. Paper presented at The 34th Annual Conference of the Cognitive Science Society (CogSci2012), Sapporo, Japan.

\section{Appendix A}

Arabic letters frequencies (connected, un-connected in different shapes as a function of word-position), according to Al-Muhtaseb, Mahmoud, \& Qahwaji (2009)

\begin{tabular}{|c|c|c|c|c|c|}
\hline & & Basic & Initial & Medial & Final \\
\hline & & \multicolumn{4}{|c|}{ Connected Letters } \\
\hline 1 & ب & 15541 & 140434 & 67938 & 9922 \\
\hline 2 & ت & 6132 & 29353 & 35826 & 27033 \\
\hline 3 & $ث$ & 2261 & 49989 & 8749 & 4368 \\
\hline 4 & ج & 2964 & 23817 & 13394 & 1496 \\
\hline 5 & $\tau$ & 3258 & 69860 & 31432 & 3388 \\
\hline 6 & $\dot{\tau}$ & 243 & 22807 & 7089 & 264 \\
\hline 7 & $w$ & 5836 & 75992 & 25487 & 7233 \\
\hline
\end{tabular}




\begin{tabular}{|c|c|c|c|c|c|}
\hline 8 & $\dot{ش}$ & 330 & 15469 & 13647 & 1647 \\
\hline 9 & $\omega$ & 481 & 32115 & 13835 & 896 \\
\hline 10 & $\dot{~ ض}$ & 1562 & 8791 & 6677 & 1481 \\
\hline 11 & $b$ & 414 & 4504 & 10245 & 1170 \\
\hline 12 & ظ & 40 & 925 & 2599 & 955 \\
\hline 13 & $\varepsilon$ & 1963 & 136499 & 54625 & 11170 \\
\hline 14 & $\dot{\varepsilon}$ & 217 & 5536 & 4608 & 483 \\
\hline 15 & ف & 2334 & 76296 & 18397 & 3655 \\
\hline 16 & ق & 4966 & 64630 & 36482 & 3497 \\
\hline 17 & ك & 3076 & 29424 & 20548 & 13896 \\
\hline 18 & J & 68146 & 242196 & 196946 & 26147 \\
\hline 19 & م & 14831 & 80246 & 80934 & 62246 \\
\hline 20 & $\dot{u}$ & 41669 & 49601 & 103031 & 130747 \\
\hline 21 & 0 & 10781 & 33486 & 37409 & 122380 \\
\hline \multirow[t]{2}{*}{22} & ي & 9800 & 76211 & 120189 & 72091 \\
\hline & & \multicolumn{4}{|c|}{ Unconnected Letters } \\
\hline 1 & 1 & 88000 & 88000 & 296148 & 296148 \\
\hline 2 & د & 18950 & 18950 & 114451 & 114451 \\
\hline 3 & $j$ & 13526 & 13526 & 15441 & 15441 \\
\hline 4 & $\jmath$ & 56138 & 56138 & 115896 & 115896 \\
\hline 5 & j & 8623 & 8623 & 12608 & 12608 \\
\hline 6 & 9 & 111734 & 111734 & 81885 & 81885 \\
\hline
\end{tabular}

